\title{
Marketing territorial aplicado a distritos industriais: estratégia de inovação para empreendedorismo e desenvolvimento local
}

\author{
Territorial marketing applied to industrial districts: innovation strategy for \\ entrepreneurship and local development
Marketing territorial aplicado a distritos industriales: estrategia de innovación para espíritu empresarial y desarrollo local

\author{
Juliana da Fonseca Capssa Lima Sausen ${ }^{1}$ \\ Jorge Oneide Sausen ${ }^{1}$ \\ Daniel Knebel Baggio ${ }^{1}$ \\ Sérgio Luís Allebrandt ${ }^{1}$
}

Recebido em 13/06/2019; revisado e aprovado em 13/01/2020; aceito em 07/02/2020

DOI: http://dx.doi.org/10.20435/inter.v22i1.2602

\begin{abstract}
Resumo: O distrito industrial é importante para o desenvolvimento econômico e social, local e regional, enquanto o marketing territorial é relevante para a implementação de ações de empreendedorismo e desenvolvimento. Considerando o potencial de indústrias, as demandas do Corede Noroeste Colonial, no Rio Grande do Sul, e os distritos industriais e o marketing territorial como base teórico-conceitual, o objetivo deste trabalho foi identificar, compreender e analisar as limitações e oportunidades das áreas industriais desta região, diante do seu contexto, articulações e dinâmicas de empreendedorismo e desenvolvimento, à luz das estratégias de marketing territorial. Foram realizadas entrevistas com agentes públicos e gestores empresariais das áreas industriais desta localidade. Verificou-se a expansão de mercado das indústrias, diversidade de produtos e serviços, bem como conscientização dos envolvidos quanto à relevância da interação e cooperação entre atores e dos processos de inovação para o desenvolvimento destas áreas. Constatou-se, porém, demandas quanto à visão empreendedora dos atores, regularização das áreas, infraestrutura, logística e recursos, fatores estes comprometedores do empreendedorismo e desenvolvimento local. Concluiu-se que tais aspectos demandam estratégias de marketing territorial para fortalecer a cooperação entre agentes públicos e privados, contribuindo para captar recursos e desenvolver as dinâmicas territoriais por meio de ações eficazes de governança, empreendedorismo e inovação.
\end{abstract}

Palavras-chave: áreas industriais; marketing; desenvolvimento territorial.

Abstract: The industrial district is important for economic and social, local and regional development, while territorial marketing is relevant to the implementation of entrepreneurship and development actions. Considering the potential of industries, the demands of Corede Noroeste Colonial, in Rio Grande do Sul, and the industrial districts and territorial marketing as a theoretical-conceptual basis, the objective of this work was to identify, understand and analyze the limitations and opportunities of industrial areas of this region, given its context, articulations and dynamics of entrepreneurship and development, in the light of territorial marketing strategies. We conducted interviews with public agents and business managers in the industrial areas of this location. There was an expansion of the market of industries, diversity of products and services, as well as awareness of those involved regarding the relevance of interaction and cooperation between actors and of innovation processes for the development of these areas. There were, however, demands regarding the entrepreneurial vision of the actors, regularization of areas, infrastructure, logistics, and resources, factors that compromise entrepreneurship and local development. We concluded that such aspects demand territorial marketing strategies to strengthen cooperation between public and private agents, contributing to raise funds and develop territorial dynamics through effective actions of governance, entrepreneurship, and innovation.

Keywords: industrial areas; marketing; territorial development.

Resumen: El distrito industrial es importante para el desarrollo económico y social, local y regional, mientras que el marketing territorial es relevante para la implementación de acciones de emprendimiento y desarrollo. Teniendo en cuenta el potencial de las industrias, las demandas de Corede Noroeste Colonial, en Rio Grande do Sul, y los distritos industriales y el marketing territorial como base teórico-conceptual, el objetivo de este

\footnotetext{
${ }^{1}$ Universidade Regional do Noroeste do Estado do Rio Grande do Sul (UNIJUÍ), ljuí, Rio Grande do Sul, Brasil.
} 


\begin{abstract}
trabajo fue identificar, comprender y analizar las limitaciones y oportunidades de las áreas industriales. de esta región, en vista de su contexto, articulaciones y dinámicas de emprendimiento y desarrollo, a la luz de las estrategias de marketing territorial. Se realizaron entrevistas con agentes públicos y gerentes de negocios en las áreas industriales de esta ubicación. Hubo una expansión del mercado de industrias, diversidad de productos y servicios, así como conciencia de los involucrados en cuanto a la relevancia de la interacción y la cooperación entre los actores y de los procesos de innovación para el desarrollo de estas áreas. Sin embargo, hubo demandas con respecto a la visión emprendedora de los actores, la regularización de áreas, infraestructura, logística y recursos, factores que comprometen el emprendimiento y el desarrollo local. Se concluyó que tales aspectos demandan estrategias de marketing territorial para fortalecer la cooperación entre agentes públicos y privados, contribuyendo a recaudar fondos y desarrollar dinámicas territoriales a través de acciones efectivas de gobernanza, emprendimiento e innovación.
\end{abstract}

Palabras claves: zonas industriales; marketing; desarrollo territorial.

\title{
1 INTRODUÇÃO
}

Diante do cenário de competitividade, de constantes transformações que envolvem as dinâmicas territoriais de desenvolvimento e em uma economia em que a inovação é elemento essencial de competitividade (BAUER, 1999; TIDD; BESSANT, 2015), estratégias diferenciadas surgem como alternativas para melhorar os contextos, as articulações entre os atores e as dinâmicas, de modo a construir vantagens sustentáveis para os territórios.

Com base nisto, o debate acadêmico em torno do desenvolvimento local e regional vem abordando discussões sobre distritos industriais, clusters, redes, sistemas e arranjos locais de produção, temas que se constituem em velhas-novas estratégias de desenvolvimento de empresas, regiões e nações. Também é comum identificar manifestações de administrações locais no sentido de fomentar os distritos industriais como elemento de importante contribuição para o desenvolvimento econômico e social, municipal e/ou microrregional. Compreendido como uma área definida pela administração pública local, por meio de um sistema produtivo, planejado, ampliado e integrado, destinado à ocupação exclusiva de indústrias; o distrito industrial procura integrar formas especializadas, territorialização, mercado de trabalho e atividades de cooperação entre empresas que, a priori, deveriam resultar em inovação, em competição e em desenvolvimento local (KELLER, 2008).

Paralelamente a isto, o marketing territorial tem sido considerado estratégia relevante para a implementação de ações inovadoras de empreendedorismo e desenvolvimento. Assim, vem a ser uma ferramenta de promoção econômica das cidades, na realização de grandes eventos, em reestruturações urbanas profundas e para a promoção turística dos territórios, empresas e das pessoas, afirmando-se como um processo de gestão territorial, descentralização de poder e busca de desenvolvimento local, de forma a integrar as vantagens competitivas do lugar sob uma ótica de desenvolvimento socioeconômico e territorial (FERNANDES; GAMA, 2006a).

Considerando tais aspectos, a potencialidade industrial, demandas de desenvolvimento dos municípios do Conselho Regional de Desenvolvimento (Corede) Noroeste Colonial do Rio Grande do Sul e a representatividade desta região para o estado, este estudo buscou identificar, compreender e analisar as limitações e oportunidades das áreas industriais nos municípios desta região, diante de seu contexto, articulações entre os atores envolvidos e dinâmicas territoriais de empreendedorismo e de desenvolvimento, à luz de estratégias de marketing territorial, para contribuir com processos de desenvolvimento local e regional. 
Primeiramente, é abordado o referencial teórico, incluindo a inter-relação dos distritos industriais com as dinâmicas territoriais de desenvolvimento e a relevância do marketing territorial como ferramenta estratégica inovadora e colaborativa para o desenvolvimento e empreendedorismo local e regional neste contexto de aglomeração produtiva. Em seguida, consta a metodologia. Após, são apresentados os resultados, incluindo análise contextual das empresas e áreas industriais do Corede Noroeste Colonial, articulação entre atores envolvidos, dinâmicas territoriais de empreendedorismo e desenvolvimento e fatores consequenciais das estratégicas de marketing territorial para o desenvolvimento das empresas e áreas industriais desta região. Por fim, encontram-se as considerações finais e as referências utilizadas.

\section{DISTRITOS INDUSTRIAIS E DINÂMICAS TERRITORIAIS}

Nos debates acadêmicos acerca da questão do desenvolvimento local e regional, e considerando o gradativo contexto competitivo no mercado corporativo de bens e serviços, é comum encontrar manifestações que consideram a relevância dos distritos industriais como elemento estratégico de aglomeração produtiva para alavancar e otimizar os processos territoriais de desenvolvimento socioeconômico, em nível local e regional, tornando-se, indispensável a compreensão de seus principais conceitos, contextos e perspectivas.

A origem do conceito de distrito industrial é atribuída ao economista inglês Alfred Marshall, que, já no início do século passado, enfatizava que as vantagens advindas das economias de escala poderiam ser obtidas por um conjunto de pequenas empresas, em território específico, especializadas em diversas fases de produção, fazendo uso do mercado de trabalho local, por meio do estabelecimento de contratos de longo prazo entre fornecedores e compradores, contribuindo para o permanente capital moderado com boas perspectivas em um longo prazo de crescimento e de emprego nos distritos (KELLER, 2008).

$\mathrm{Na}$ década de 1970, economistas italianos retomaram o conceito marshalliano por meio de Becattini, para identificar as bem-sucedidas aglomerações de pequenas empresas no centro-norte da Itália, marcadas por avanços tecnológicos e elevada internacionalização (LIMA; NETO, 2019). Conforme Putnam (1996), este modelo fundamentava-se em uma forma intermediária de organização de produtores, por meio de aliança informal e apoio dos governos.

As duas principais características das abordagens teóricas dos distritos industriais que aparecem na literatura são: a ênfase na rede de firmas como fator-chave da constituição do distrito industrial típico, com empresas relativamente pequenas e verticalmente não integradas; e, mais recentemente, a ênfase no enraizamento da rede de firmas no sistema social local, considerando as características do território (tecido social local) para empreender e a análise do surgimento e da transformação dos distritos industriais (KELLER, 2008).

Ou seja, diferentemente das concepções tradicionais deste tipo de aglomeração produtiva, as novas concepções de distrito industrial apresentam a vantagem de incorporar, em suas análises, o conceito de produção flexível, além de uma avaliação das sinergias geradas como resultantes não apenas de relações mercantis, mas, sobretudo, de aspectos culturais, sociais e históricos comuns, presentes nos territórios, conforme destaca Becattini (1990).

Bauer (1999) corrobora esta visão ao afirmar que a imposição de adaptação do mercado às organizações proporcionou que atributos como flexibilidade e criatividade adquirissem mais importância, constituindo um cenário em que produtos e serviços são valorizados pela 
produtividade e inovação. Neste caso, a inovação consiste não apenas na abertura de novos mercados, mas em novas formas de servir mercados já estabelecidos, por meio da criação ou melhoria de produtos e processos contínuos de aprendizagem, conhecimento e aperfeiçoamento no interior das organizações (TIDD; BESSANT, 2015).

Paralelamente a isto, a interação entre os agentes locais, tendo como base a cooperação e a concorrência, é que determina os rumos do crescimento local, sendo que a flexibilidade organizacional se dá por meio de uma rede de empresas especializadas, dotadas de grande capacidade de inovação e concretizadas por meio de relações horizontais, nas quais se processam a aprendizagem coletiva e o desenvolvimento de novos conhecimentos (OLIVEIRA, 2005).

Desta forma, o distrito industrial é marcado pelo surgimento de formas implícitas e explícitas de cooperação entre agentes econômicos locais e pelo surgimento de fortes associações empresariais setoriais, sendo considerado um cluster maduro ou que desenvolveu suas potencialidades atingindo sua eficiência coletiva. A partir daí, Keller (2008) pontua o conceito de "eficiência coletiva" como a vantagem competitiva derivada das economias externas e da ação conjunta. A especialização flexível engloba, portanto, aspectos de cooperação, ancorados na confiança entre atores sociais e organizacionais, na cultura local e na rede de interações entre os diferentes agentes envolvidos na dinâmica do desenvolvimento.

Diante do contexto de transformações, as gestões cada vez mais vêm ressaltando a necessidade de fomentar o dinamismo e as vantagens competitivas de cada território ou cidade (OLIVEIRA, 2005). Para tanto, as empresas precisam se reorganizar para responder de maneira rápida e flexível às mudanças de mercado desencadeadas pela crise da produção em massa, implicando a consolidação de uma unidade territorial de produção integrada.

E, com o reconhecimento da importância dos novos espaços para o crescimento das economias regionais (OLIVEIRA, 2005), o desenvolvimento pode ser considerado um processo de mudança estrutural e crescimento econômico no qual a organização do sistema produtivo, a rede de relações entre atores e atividades, a dinâmica de aprendizagem e o sistema sociocultural são importantes no processo de mudança. O território, nesta abordagem, é percebido como agente de transformação social, um emaranhado de interesses comunitários.

Assim sendo, a acumulação de capital e o progresso tecnológico são fatores-chave nesse processo, e os fatores determinantes da acumulação de capital são reconhecidos como a criação e difusão de inovações no sistema produtivo; a organização flexível da produção; a geração de economias de aglomeração e de diversidade nas cidades; e o fortalecimento das instituições (DALLABRIDA; SIEDENBERG; FERNÁNDEZ, 2004). É preciso, ainda, o incentivo à cooperação, por meio da compreensão dos processos sociais expressando práticas de grupos de atores que permeiam o aprendizado, o compartilhamento de conhecimentos, bem como a construção conjunta de identidades (VILLASCHI FILHO; CAMPOS, 2002). E, neste contexto todo, o marketing territorial se configura como uma importante estratégia de desenvolvimento para as cidades, suas localidades e para as aglomerações produtivas locais.

\section{MARKETING TERRITORIAL: INOVAÇÃO PARA O DESENVOLVIMENTO}

O marketing territorial tem evoluído notoriamente. Seu conceito foi introduzido por Kotler, Haider e Rein (1993), por meio de uma nova abordagem designada de marketing estratégico de lugares, comparando, pela primeira vez, na literatura, as cidades a um produto (ARAGONEZ; 
ALVES, 2013); nos anos 1980, a sua emergência começou a ser notada, na medida em que surgiu como resposta a um processo geral de estagnação, comum em várias cidades, considerando também que a globalização da economia contribuiu para a disseminação dos espaços competitivos, levando as cidades e as regiões a se posicionarem.

No contexto de desenvolvimento das tecnologias de informação e comunicação, a afirmação recente dos territórios do conhecimento contribuiu para a ascensão do marketing do lugar, que aposta em diferentes esferas da cidade e em elementos-chave, como redes, liderança, recursos humanos, destacando a identidade local, especificidade, percepção do lugar e criatividade como elementos essenciais para a revitalização e vitalidade econômica, social e cultural de uma cidade, região ou país (FERNANDES; GAMA, 2006a).

Iniciativas locais dependem de um bom desenvolvimento territorial que considere as características do local e de sua população, potencializando-as e visando à satisfação das necessidades humanas (OLIVEIRA; BORGES, 2018). A localização e concentração de conhecimento e indústrias podem facilitar o aumento da atratividade e a promoção do lugar por meio de estratégias de marketing territorial (FERNANDES; GAMA, 2006b). Neste quadro, os territórios precisam desenvolver estratégias de afirmação, promoção e mobilização de recursos, procurando atrair e fixar bens, capital humano, recursos financeiros e investimentos, de forma a alterar a representação espacial e influenciar a percepção das regiões e cidades.

O marketing territorial é desafio de criatividade, organizacional e de comunicação, o qual surge como um dos elementos centrais do planejamento estratégico das cidades e regiões, partindo de suas singularidades e especificidades, integrando-as, projetando-as, promovendo-as e afirmando-as em um contexto global de competitividade (FERNANDES; GAMA, 2006a; KUTTUBAEVA et al., 2017; RIZZI; CICIOTTI; GRAZIANO, 2018). Assim, deve-se reforçar a participação e integração, no intuito da inovação, e o fortalecimento de estratégias que considerem a passagem do marketing do lugar para o desenvolvimento do lugar.

$E$, no contexto de desenvolvimento e inovação, a relação com os sistemas locais de aglomeração, especificamente com os distritos industriais, torna-se fundamental. Aglomerações produtivas constituem cenário territorial propício, já que são potencialmente espaços privilegiados que podem vir a contribuir para o surgimento e desenvolvimento de constructos socioculturais de conhecimento, aprendizado e inovação interativos (ALBAGLI; MACIEL, 2004). A abordagem dos meios inovadores também tem muita relação com a dos distritos industriais (DALLABRIDA; SIEDENBERG; FERNÁNDEZ, 2004).

A partir desta perspectiva, é possível compreender a oportunidade competitiva do contexto geográfico, definir uma orientação estratégica eficaz em função de uma oportunidade e dos agentes envolvidos, estimular a atuação, realizar intervenções e promover estratégias eficazes de comunicação direcionadas aos públicos atuais e potenciais. Lembrando que a concretização positiva destas ações considera a interação, integração e cooperação de diversos atores em prol de objetivos comuns, remetendo aos conceitos de ação conjunta e eficiência coletiva como elementos indispensáveis para a disseminação do conhecimento, aprendizagem e inovação de vantagem competitiva nos territórios dos distritos industriais.

E embora a implementação das novas políticas urbanas seja divulgada pelos governos locais, pouco se discute sobre a formação de coalizões de interesses para tornar as cidades atraentes (OLIVEIRA, 2005). Assim, o marketing territorial é o processo que considera a capacidade de envolver diferentes atores para criar novas ideias, desenvolver políticas e implementá-las, 
pressupondo outras formas de observar e pensar o território, permitindo sua sustentabilidade social, econômica, cultural e política (FERNANDES; GAMA, 2006a).

Importa que os grupos atendam e desenvolvam estratégias que potenciem e tornem públicos os principais fatores de atratividade, como os hard factors - estabilidade econômica, níveis de produtividade, custos, serviços locais de apoio, localização, tecnologias e incentivos financeiros - e os soft factors, associados à dimensão mais intangível do território - qualidade de vida, cultura, empreendedorismo, flexibilidade e dinamismo (GAIO; GOUVEIA, 2007).

Em termos estratégicos de marketing, deve-se buscar uma identidade comercial rentável e sustentável para as cidades e localidades e, a partir desta identidade, buscar um nicho de atuação para atrair investimentos produtivos. Significa pensar qual produto deve ser a localidade, em quais praças deve ser anunciada, sob quais preços e promoções. É o que Dallabrida, Tomporoski e Sakr (2016) denominam de branding ou marca de território.

Assim, a marca e o posicionamento devem ser materializados por meio do processo de marketing mix e a imagem intencional deve ser um espelho da identidade do território (GAIO; GOUVEIA, 2007). Ainda quanto ao posicionamento, este define-se pela: vocação (domínio do território), capacidade (para manter a posição definida), ambiente (características físicas do território) e coerência (considerando todos estes aspectos) (FERNANDES; GAMA, 2006b).

Desta forma, o marketing territorial funciona como um fator de potencialização ao nível da divulgação de uma imagem a fim de atingir o público-alvo identificado, defendendo a necessidade de uma nova abordagem de planejamento das cidades e das localidades, sendo exigido um reposicionamento dos espaços urbanos, de forma a conseguir sistemas territoriais competitivos por proximidade geográfica e por meio de parcerias em nível social, político, institucional e econômico (ARAGONEZ; ALVES, 2013), sendo que este cenário também remete ao modelo de organização flexível dos distritos industriais.

A partir daí o marketing territorial potencializa uma ligação sinergética com o desenvolvimento econômico e, também, social, político e cultural dos territórios. E, ao mesmo tempo que utiliza como estratégia as vantagens competitivas das aglomerações produtivas locais, favorece a extensão da imagem e dos atributos da marca da cidade aos produtos e aglomerações locais, promovendo novas e múltiplas potencialidades no território.

\section{PROCEDIMENTOS METODOLÓGICOS}

A pesquisa deste estudo classifica-se como social e de abordagem qualitativa. Social, pois tem como campo as possibilidades de investigação da realidade social; qualitativa, na medida em que buscou aprofundar-se no mundo dos significados (MINAYO, 2016). Quanto ao nível de investigação, configura-se como pesquisa exploratória, sendo realizada em área na qual há pouco conhecimento acumulado e sistematizado (MALHOTRA, 2012).

Desta forma, este estudo abre precedentes para uma maior exploração acadêmico-científica quanto ao contexto da dinâmica de desenvolvimento territorial e suas implicações para os distritos industriais, como também quanto à relevância do marketing territorial enquanto ferramenta estratégica para a promoção do desenvolvimento territorial, tendo como foco as áreas industriais referentes aos municípios pertencentes ao Corede Noroeste Colonial.

Os Conselhos Regionais de Desenvolvimento (Coredes) são instâncias legais e regulamentadas com constituição jurídica própria em cada região, estabelecendo-se por meio de fóruns 
permanentes e autônomos de participação, discussão e decisão a respeito de políticas e ações (coletivas) para contribuição com o desenvolvimento local e regional, por meio da aproximação entre governo e instituições regionais (CARGNIN, 2011).

Conforme informações da Secretaria do Planejamento, Mobilidade e Desenvolvimento Regional do Rio Grande do Sul (PORTO ALEGRE, 2015), o Corede Noroeste Colonial pertence à Região Funcional 7 (RF7), sendo formado por 11 municípios da Macrorregião Noroeste do Estado do Rio Grande do Sul (Ajuricaba, Augusto Pestana, Bozano, Catuípe, Condor, Coronel Barros, Ijuí, Jóia, Nova Ramada, Panambi e Pejuçara), somando mais de 168 mil habitantes, com área territorial de 5 mil m² e densidade demográfica de 32,7 hab. $/ \mathrm{km}^{2}$, sendo que esta região destaca-se também pela agricultura, serviços e indústrias. Além disso, de acordo com dados apresentados pelo Fórum dos Coredes do Rio Grande do Sul (2017), no ano de 2014, o Corede Noroeste Colonial foi a única microrregião da FR7 com Índice de Desenvolvimento Socioeconômico (IDESE) alto $(0,826)$, ocupando o segundo lugar no ranking estadual.

Para alcançar os objetivos, além da pesquisa bibliográfica, principalmente em livros e artigos sobre as temáticas abordadas, foram realizadas entrevistas com 13 agentes públicos (prefeitos, vice-prefeitos e secretários) e 21 gestores de empresas dos municípios do Corede Noroeste Colonial. As entrevistas foram semiestruturadas, aplicadas pessoalmente, registradas por áudio e transcritas, sendo elaboradas e conduzidas por um grupo de pesquisa financiado pela Fundação de Amparo à Pesquisa do Estado do Rio Grande do Sul (FAPERGS).

\section{INDUSTRIALIZAÇÃO E MARKETING NO COREDE NOROESTE COLONIAL}

\subsection{Empresas e áreas industriais do Corede Noroeste Colonial}

O conceito de distrito industrial é diferente do utilizado para área industrial - que se refere ao surgimento espontâneo da indústria, sem o planejamento da área, como resultado do crescimento natural da economia local, podendo levar muitos anos para acontecer, ou até mesmo nunca acontecer (DALLABRIDA; SIEDENBERG; FERNÁNDEZ, 2004). Em paralelo, no Corede Noroeste Colonial, há trâmites a serem concluídos e ações que demandam planejamento para a concretização efetiva do que vem a ser distrito industrial.

Desta forma, a grande maioria dos municípios desta região tem áreas industriais, destacando ljuí como o município com mais áreas industriais (onze), seguido de Panambi (três), Pejuçara (duas) e outros municípios com uma área industrial cada um. Referente às empresas instaladas, ljuí tem 150, Condor tem 23 e os demais municípios não apresentaram esta informação. Não por acaso, Ijuí é responsável por aproximadamente 50\% do Produto Interno Bruto (PIB) do Corede Noroeste Colonial (FÓRUM DOS COREDES, 2017).

Entre os ramos das empresas analisadas do Corede Noroeste Colonial, destacam-se construção civil, indústria metalmecânica, indústria moveleira e agroindústria, sendo que a maioria destas empresas tem mais de duas décadas de atuação e sua instalação ocorreu geralmente na mesma época ou pouco tempo após sua efetiva instalação nos municípios.

O número de funcionários é diversificado nas empresas. Destacam-se, contudo, os municípios de ljuí e Condor com 150 funcionários. Evidenciam-se principalmente as pequenas empresas, com faixas de faturamento bruto anual acima de 360 mil reais até três milhões e 600 mil reais. Grande parte dos investimentos com produção provém de recursos próprios das empresas. A maior parte, porém, tem endividamento quanto ao ativo total. 
Boa parte dos clientes são regionais, destacando-se ainda clientes locais e de fora do estado (especialmente da região Sul do Brasil), sendo que duas empresas de ljuí e uma de Panambi costumam exportar seus produtos para fora do Brasil. A maioria dos insumos utilizados provém de fornecedores de fora do estado e de fornecedores de estados próximos.

A maior parte dos gestores das empresas é natural dos municípios onde as indústrias estão instaladas ou de municípios próximos, tem mais de 40 anos de idade, ensino médio, conhecimento básico em espanhol e inglês, e ocupa cargos de sócio-proprietário, diretor ou gerente, participando regularmente na direção de atividades relacionadas à Associação Comercial e Industrial $(\mathrm{ACl})$, a entidades religiosas e beneficentes e a clubes sociais.

De forma geral, o tempo de empresa e de atuação dos gestores nas atividades corresponde à data de fundação destas indústrias. Boa parte das indústrias é empresa familiar, agricultura e empreendedorismo são as atividades profissionais da maioria dos pais destes gestores, e há atuação de cônjuges, irmãos e filhos nas áreas administrativa, comercial e financeira das empresas. A maioria das indústrias constitui-se como o único empreendimento realizado pelos gestores até então, sendo a visão de mercado, a oportunidade de investir e a necessidade financeira os principais motivos para a constituição dos empreendimentos.

Em referência às questões legais, agentes públicos de nove dos 11 municípios da região se manifestaram sobre as leis que regulam o funcionamento das áreas industriais. Em cinco municípios, elas existem; nos municípios restantes, não há atuação destas leis e, além disso, muitas áreas industriais não têm conselho e secretaria como contato de avaliação.

Sobre os meios de comunicação utilizados para informar a população sobre as estruturas e serviços disponibilizados aos empreendedores interessados nas áreas industriais dos municípios, destacam-se editais na Internet, murais, rádios e jornais das prefeituras. Os critérios para solicitação de lotes incluem cadastros e protocolos requisitados nos editais, apresentação de Plano de Negócios, Sala do Empreendedor - projeto do Serviço Brasileiro de Apoio às Micro e Pequenas Empresas (Sebrae) - e participação em leilões. Já os critérios para concessão destes lotes são indefinidos em quase todos os municípios da região.

Entre os benefícios a priori oferecidos pela gestão pública municipal para as áreas industriais, destacam-se infraestrutura, cessão de terreno por comodato e transferência de propriedade para empresas instaladas após alguns anos e conforme resultados alcançados. Em paralelo, geração de emprego e renda, retorno fiscal e aumento de ICMS são os principais benefícios e contrapartidas esperados pela gestão pública com a instalação das áreas.

\subsection{Articulações entre os atores diante de dinâmicas territoriais}

Levando em conta a importância do atendimento às demandas dos atores envolvidos (ARAGONEZ; ALVES, 2013) e da coalizão de interesses (OLIVEIRA, 2005), somados ao envolvimento de diferentes atores para desenvolver novas ideias e políticas territoriais, (FERNANDES; GAMA, 2006a), considera-se relevante apresentar as articulações entre os atores diante das dinâmicas das áreas industriais da região Corede Noroeste Colonial.

Apesar de alguns empresários assumirem cargos diretivos na gestão pública e de haver agentes públicos com formação em administração, muitos entrevistados afirmam haver pouca interação e cooperação entre empresas e agentes públicos na consolidação das áreas industriais, apesar de considerarem estas práticas fundamentais para o seu desenvolvimento. 
Em referência aos projetos e programas utilizados pelos municípios para garantir as repercussões esperadas para as áreas industriais, foram citadas pelos agentes públicos as parcerias com o Sebrae, Serviço Nacional de Aprendizagem Industrial (Senai), Conselhos Municipais de Desenvolvimento (COMUDEs), Secretarias de Planejamento e de Desenvolvimento Econômico e as associações comerciais dos respectivos municípios.

Contudo, na visão dos empresários entrevistados, a importância das interações com os atores para a otimização de projetos e ações de desenvolvimento voltadas às áreas industriais varia bastante. Ou seja, com empresários do distrito e fora do distrito, conselhos municipais, sistema S (Senai, Sesi, Sebrae) e Associação Comercial e Industrial, o grau de importância das interações vai de irrelevante a imprescindível - sendo imprescindível com membros do governo municipal, e irrelevante com consultores e, principalmente, com os sindicatos.

Além disso, as interações com estes atores, muitas vezes, não acontecem ou acontecem com pouca frequência. Quanto às interações informais, a maioria dos gestores empresariais costuma reunir-se eventualmente. Isto é, os gestores costumam reunir-se semanalmente com amigos, menos de uma vez por mês com colegas de trabalho e em festas municipais, e não costumam participar de reuniões em associações comunitárias. Percebe-se, portanto, que, apesar de os gestores considerarem as interações relevantes para o desenvolvimento local e regional, estas não costumam ser muito significativas no cotidiano.

Confiança e solidariedade também estão aquém. No contexto e em relação aos municípios, para grande parte dos empresários entrevistados, apesar de a maioria das pessoas estar disposta a ajudar caso precise, não há confiança nestas; é preciso estar atento para que não tirem vantagem e as pessoas geralmente não confiam umas nas outras quanto a emprestar e tomar dinheiro emprestado. Além disso, as universidades, seguidas de empresários do distrito e de consultores contratados, são os atores que mais inspiram confiança, enquanto os sindicatos são os atores que menos transmitem confiabilidade para os empresários.

Nas áreas industriais, destacam-se como articuladores os gestores de órgãos públicos, de empresas de renome e pessoas envolvidas com entidades beneficentes. Contudo, há poucos atores articuladores e pouca ou nenhuma participação social destes atores na gestão das áreas. E, apesar de a maioria dos empresários considerar a cooperação de empresários quanto a abastecimento de água, empréstimo de máquinas e indicação de produtos próprios e de outras empresas de sua área industrial para os clientes, a transferência de tecnologia, busca de novos mercados, aprendizagem e cooperação acontecem com pouca frequência nas áreas industriais. É pouco frequente também a promoção de debates, treinamentos, esclarecimentos e proposições por parte do poder público. Portanto, de modo geral, iniciativas e ações coletivas não são frequentes, sendo que as ações realizadas ficam restritas a reuniões pontuais para solucionar questões referentes à instalação, infraestrutura e segurança das áreas industriais.

Assim, com base nestes pressupostos, verifica-se que, de fato, existe pouca cooperação na relação das empresas entre si e destas com os setores públicos, no sentido de viabilizar o desenvolvimento nas áreas industriais. Segundo um agente público do município de ljuí: "Os empresários têm dificuldades de visão, de crescer. Por outro lado, precisamos facilitar a vida do empreendedor na busca de recursos". Estes aspectos evidenciam, ainda, o individualismo, acarretado principalmente pela concorrência entre as empresas. Conforme um empresário de Catuípe: "É cada um por si". Porém, na visão de um empresário de Panambi: "Todo mundo tem ideias e precisa entender que essas ideias serão úteis para todos crescerem". 


\subsection{Dinâmicas territoriais de empreendedorismo e desenvolvimento}

Junto da análise do perfil das empresas e das áreas industriais do Corede Noroeste Colonial e das articulações entre os atores envolvidos nos processos, as dinâmicas territoriais de empreendedorismo e desenvolvimento também são importantes para a compreensão das limitações e oportunidades na região, como contribuição para o desenvolvimento territorial.

Em referência aos instrumentos e mecanismos de gestão das indústrias analisadas, planos de negócio costumam ser desenvolvidos, porém, na prática, as ações são implementadas de acordo com imprevistos e demandas do dia a dia. Participações em feiras não acontecem com frequência. Orçamentos de caixa e contabilidades de custos, de forma geral, são utilizados. Planos estratégicos, bem como avaliações e indicadores de desempenho, precisam ser mais bem instrumentalizados, uma vez que estes processos ocorrem mais informalmente. No que se refere ao Balanced Scorecard (mede o desempenho empresarial por meio de indicadores quantificáveis e verificáveis) e Canvas (permite desenvolver e esboçar modelos de negócio), boa parte das empresas desconhece tais ferramentas, e as que conhecem as utilizam pouco.

De forma geral, os gestores das indústrias consideram o acesso a novas tecnologias de produtos e processos, a mão de obra qualificada, os capitais de giro e de investimento, o custo relativo dos produtos e a infraestrutura do distrito industrial aspectos relevantes para a competitividade e o crescimento do negócio. Já o transporte e a logística (provenientes de recursos próprios) ficam em segundo plano, assim como as mídias sociais e digitais, pois muitas destas indústrias utilizam o contato interpessoal como principal meio de comunicação

Quanto aos processos (contabilidade fiscal e de custos; automação comercial; gestão do relacionamento com clientes; planejamento e indicadores; e orçamento de caixa), de maneira geral, são operacionalizados pelas próprias empresas (com exceção da contabilidade fiscal, que costuma ser terceirizada), informatizados, não estão integrados a outros sistemas (excetuando-se a contabilidade de custos), informações são utilizadas em períodos diversos (diário, semanal, mensal e eventual), e a satisfação com tais processos também varia.

No que condiz aos produtos e processos, grande parte das mudanças ocorre anualmente (acréscimo de novas funcionalidades, mudanças no processo de produção e de insumos/ componentes) e mensalmente (correção de falhas, mudanças nos custos/preços). Além disso, a pesquisa interna realizada nas empresas, as sugestões de clientes e a participação em feiras são os principais fatores que originam inovações nas empresas.

Enquanto vantagem competitiva de inovação (TIDD; BESSANT, 2015), foram destacadas a qualidade, a exclusividade, a inovação dos atributos e a pontualidade na entrega dos produtos e serviços. Agentes do setor público e privado concordam quanto à relevância da inovação para o sucesso dos negócios: "Tem que estar sempre criando, inovando" (empresário de Jóia), "Uma política industrial precisa prever mecanismos de inovação, se o empreendedor não busca novos conhecimentos e tecnologias para aproveitar o que tem disponível no mercado, vai ser diferente daquele que busca" (agente público de ljuí). Paralelamente a isto, apesar de as empresas não terem o costume de se inspirar em outras experiências de área ou distrito industrial, a maioria delas teve expansão de mercado nos últimos três anos.

No que condiz aos fatores críticos para o sucesso das empresas das áreas industriais, os entrevistados apontam principalmente a falta de recursos (mão de obra qualificada, acesso logístico e recursos financeiros). "Evolui quem tem mais recursos próprios para investir" (agente público de Pejuçara). Isso porque muitas empresas demandam de recursos externos e "o poder 
público está mantendo o que é básico" (empresário de Jóia); ou seja, "o recurso é limitado, não existe recurso para ter uma repercussão efetiva" (agente público de Panambi).

A falta de recursos, juntamente da falta de incentivos e investimentos do estado, é gerada, inclusive, pela instabilidade econômica do país, que desencadeia outros fatores, tais como: demanda de empresas locais para investir e dependência de pequenas empresas em relação a empresas maiores e mais consolidadas. Ainda, em decorrência da incipiência do projeto dos distritos industriais nos municípios em análise, evidencia-se a falta de competitividade nos custos dos produtos e serviços das empresas nas áreas industriais.

Quantos aos elementos de composição da política nas áreas industriais, constatam-se: mecanismos insuficientes para gerar inovação e demanda de fomentos de setores e de geração de externalidades. São evidenciadas, também, demandas quanto à: sinergia entre empresas e destas com o poder público; regulamentação e monitoramento de leis para atender a diferentes necessidades e interesses das empresas beneficiadas e de suas respectivas áreas; utilização de áreas recebidas para alavancar financiamentos diante das restrições das políticas de concessão de terrenos; estrutura efetiva de governança que envolva o estado e as empresas beneficiadas; formalidade de metas; e política industrial articulada e planejada nestes espaços.

Paralelamente a isto, quase todos os empresários desconhecem políticas para beneficiar seu empreendimento e área industrial. Portanto, na maioria dos casos, o potencial de desenvolvimento da região a partir da configuração das áreas industriais tem se mostrado, em termos técnicos e políticos, bastante limitado e restrito a iniciativas isoladas e individualizadas, restringindo os processos de desenvolvimento e de empreendedorismo.

Também, apesar de algumas indústrias já terem passado por processos ambientais, trabaIhistas e fiscais, e da maioria destas indústrias realizar poucas e eventuais ações sociais (ações internas para colaboradores e suas famílias; arrecadações e doações em dinheiro; e doações de produtos e materiais para entidades beneficentes), os empresários afirmam preocupar-se com a sustentabilidade de suas empresas perante o mercado e a sociedade.

Portanto, levando em conta todos estes aspectos, são destacados caminhos pontuais para melhor organização, manutenção e potencialização destas áreas, tais como: planejamento estratégico de longo prazo, maior divulgação do projeto (empresas, áreas industriais, produtos e serviços), infraestrutura (água, luz, terraplanagem, energia solar, acesso, sinalização, coleta seletiva, descarte e reciclagem de lixo), mão de obra qualificada, logística e distribuição, produtos benéficos para a sociedade, redefinição de políticas de financiamento e de concessão de terrenos, implementação de políticas específicas de investimentos em distritos e áreas industriais, e destinação de parte do lucro das áreas industriais para investimento nestas.

Para maior otimização das ações, destaca-se a qualificação dos agentes públicos e privados em prol de uma visão mais contextual e empreendedora: "Desenvo/vimento é o todo, é construção, sistema em rede, precisamos despertar para o senso do empreendedorismo, e aí entram a universidade, as pessoas, as entidades, o envolvimento dos atores procurando valorizar os recursos locais para investir" (agente público do município de ljuí).

Por fim, as estratégias e ações convergem para a relevância de maior cooperação entre empresas, e destas com entidades e atores do poder público: "O desenvolvimento são as pessoas, então é fundamental que as instituições se conversem, se aproximem e há uma necessidade dos empresários enxergarem que o vizinho não é concorrente, precisa haver essa convivência, podemos crescer juntos" (agente público do município de ljuí). 


\subsection{Marketing territorial aplicado às áreas industriais do Corede Noroeste Colonial}

Considerando que o marketing territorial surge como um dos elementos centrais do planejamento estratégico das cidades e regiões (FERNANDES; GAMA, 2006a), para que possa constituir-se efetivamente como estratégia de otimização das dinâmicas de desenvolvimento das áreas industriais do Corede Noroeste Colonial, deve estar integrado ao planejamento estratégico dos projetos de desenvolvimento direcionados a este território.

Assim, deve primeiro realizar o diagnóstico de seu objeto de intervenção, considerando contextos, articulações, dinâmicas, limitações e oportunidades referentes a este objeto; e, por ser uma ferramenta de marketing, o diagnóstico leva em conta os 4Ps do mix de marketing produto, preço, praça e promoção (GAIO; GOUVEIA, 2007).

Projetando os municípios do Corede Noroeste Colonial como o produto, e as áreas e empresas industriais como subprodutos ou atributos que possam vir a agregar valor para este produto, percebe-se que - apesar do potencial mercado de indústrias e da variedade em produtos e serviços identificados especificamente neste território - tais atributos estão aquém das demandas e expectativas para tal finalidade, principalmente quanto aos elementos que poderiam contribuir para seus aspectos tangíveis (relações de governança, gestão e inovação em produtos e processos, infraestrutura das áreas industriais e mão de obra).

Referente ao fator preço e como consequência das limitações de atributos para a implementação e o desenvolvimento das indústrias analisadas, evidencia-se a falta de competitividade nos preços dos produtos e serviços ofertados por estas empresas. Tal realidade - somada à falta de recursos financeiros em consequência da instabilidade econômica do cenário nacional, bem como à falta de incentivos e investimentos do estado e demais agentes públicos - pode gerar empecilhos à sustentabilidade destas empresas em médio e longo prazos, tanto em relação ao território como também diante do mercado industrial. Quanto à praça, isto é, quanto às questões logísticas e de distribuição dos produtos e serviços ofertados pelas empresas das áreas industriais do Corede Noroeste Colonial, a dificuldade de acesso dos fornecedores, clientes e demais agentes envolvidos - ocasionada pela distância geográfica entre as áreas industriais e centrais dos respectivos municípios, bem como pelas más condições das estradas - aparece como um dos principais entraves.

Outro aspecto relevante refere-se à necessidade de maior efetividade e otimização dos canais de distribuição quanto à variedade, interatividade e ampliação de atuação territorial, identificada pela pouca demanda de indústrias locais para instalação nas áreas e pela falta de maior interação e colaboração do poder público com as indústrias e destas entre si, limitando a arrecadação de recursos para tal fim, tanto em nível local como em contextos mais amplos.

Por fim, no que diz respeito à promoção, ou seja, às estratégias e ações de comunicação e de divulgação elaboradas e implementadas para as empresas estabelecidas nas áreas industriais, estas restringem-se às informações sobre legislações, procedimentos, estruturas e serviços disponibilizados aos empreendedores interessados em tais áreas, sendo que pouca ou nenhuma estratégia ou ação é direcionada para a comunicação e divulgação acerca da relevância das áreas industriais e de seus produtos, serviços e processos para o desenvolvimento dos municípios, dos atores envolvidos e da sociedade local e regional.

Realizado o diagnóstico das áreas e indústrias do Corede Noroeste Colonial, o próximo passo consiste em promover estratégias e ações para a otimização dos processos que permeiam estas áreas e indústrias, para fins de fortalecer o desenvolvimento, a identidade e a imagem 
deste território, possibilitando benefícios aos municípios e a todos os agentes envolvidos nesta dinâmica de desenvolvimento, inclusive para a sociedade local e regional.

Levando em conta a relevância, a inter-relação e a demanda por melhorias identificadas nos 4 Ps do mix de marketing, verifica-se a necessidade de implementação de estratégias e ações de marketing territorial integradas e que, ao mesmo tempo, contemplem cada uma destas dimensões, buscando materializar e fortalecer a imagem, o posicionamento e a marca das empresas e áreas industriais do Corede Noroeste Colonial, assim como promover uma identidade comercial rentável e sustentável para este território (GAIO; GOUVEIA, 2007). Assim, são necessárias estratégias e ações para captação de recursos financeiros, possibilitando melhorias em infraestrutura, tecnologia, mão de obra, logística, gestão e inovação de produtos e processos; maior implementação, reestruturação e monitoramento de políticas e leis para o funcionamento das áreas industriais; comunicação e divulgação com foco nas potencialidades das empresas e áreas e no desenvolvimento territorial; e estabelecimento de ações eficazes de governança, empreendedorismo, gestão e inovação que permitam colocar em prática o planejamento estratégico nestes aglomerados.

E embora os agentes públicos e privados reconheçam as demandas evidenciadas e a relevância de estratégias e ações que possam suprir tais demandas e contribuir para a positiva projeção das empresas e das áreas industriais do Corede Noroeste Colonial, é também importante que estes aspectos sejam permeados por uma restruturação e fortalecimento da participação, inter-relação e cooperação entre os agentes envolvidos nos processos de desenvolvimento territorial, abrangendo parcerias em nível político, econômico, social e cultural (ARAGONEZ; ALVES, 2013). Afinal, é fundamental, para uma estratégia de marketing territorial, que haja condições e vontades, concertadas por diferentes agentes de uma forma única, coesa e coerente (FERNANDES; GAMA, 2006a), contribuindo para a reconfiguração e otimização do empreendedorismo e desenvolvimento na região em estudo.

\section{CONSIDERAÇÕES FINAIS}

Partindo da afirmação de que os distritos industriais e o marketing territorial são relevantes para o desenvolvimento local e regional, para o potencial mercado de indústrias e para as demandas de desenvolvimento do Corede Noroeste Colonial, este artigo cumpriu os objetivos de identificar, compreender e analisar as limitações e oportunidades das áreas industriais desta região, diante dos contextos, das articulações e dinâmicas de empreendedorismo e desenvolvimento, à luz das estratégias de marketing territorial.

Quanto à análise contextual das empresas e áreas industriais do Corede Noroeste Colonial, a maioria dos municípios desta região apresenta áreas industriais, empresas e gestores com bastante tempo de atuação no mercado, e diversidade em produtos e serviços. Contudo, são evidenciadas demandas quanto à concretização efetiva dos distritos industriais nesta porção territorial, regularização e acompanhamento nas áreas industriais e investimento em capacitação empreendedora para os empresários atuantes nestas localidades.

Sobre as articulações entre os atores diante das dinâmicas territoriais, os entrevistados consideram fundamentais a interação e cooperação entre empresas e agentes públicos para a consolidação e o desenvolvimento das áreas industriais. Na prática, porém, existe pouca interação e cooperação, principalmente quanto à aprendizagem; transferência de tecnologia; busca de novos mercados; compartilhamento de informações pelo poder público; iniciativas e ações 
coletivas; e articulação e participação social dos atores na gestão das áreas. Tais aspectos remetem à competitividade e falta de assertividade, confiança e solidariedade nas relações.

No que condiz às dinâmicas territoriais, a maioria das empresas está em expansão no mercado; agentes públicos e privados consideram a inovação relevante para o sucesso dos negócios; pesquisa interna, sugestões de clientes e participação em feiras são os fatores que mais originam inovações; e estratégias de produtos e serviços estão no centro da vantagem competitiva. Porém, a falta de planejamento e visão empreendedora dos gestores, bem como de recursos, cooperação e apoio externo, compromete a inovação, sendo necessária uma estrutura de governança com uma política industrial articulada e planejada nestes espaços.

Conclui-se, ainda, que os distritos industriais e o marketing territorial estão estreitamente relacionados, por meio das similaridades em suas estratégias de desenvolvimento territorial e da interdependência entre as temáticas para a concretização eficaz de tais estratégias. Além disso, se bem planejados, articulados, implementados e comunicados, os distritos industriais e o marketing territorial constituem-se conjuntamente como estratégicas relevantes e empreendedoras, podendo contribuir de maneira diferenciada e assertiva para a promoção do desenvolvimento socioeconômico e da imagem do Corede Noroeste Colonial.

Sobre a aplicação do marketing territorial, ressalta-se primeiramente a realidade de cada um dos 4Ps do mix de marketing no contexto das áreas industriais da região em análise. Considerando o Corede Noroeste Colonial, suas áreas e empresas como um produto, apesar do potencial mercado industrial evidenciado, são constatadas lacunas de gestão, inovação, infraestrutura e mão de obra. Referente ao preço, evidencia-se a falta de competitividade nos preços dos produtos e serviços ofertados e a falta de recursos e incentivos para a sustentabilidade das empresas. No que se refere à praça, ressalta-se a dificuldade de acesso e a necessidade de variedade, interatividade e ampliação de canais de distribuição na região. Quanto à promoção, há pouca ou nenhuma ação de comunicação ou divulgação acerca da relevância das áreas industriais e de seus produtos, serviços e processos para o desenvolvimento dos municípios, dos atores envolvidos e da sociedade local e regional.

Portanto, ao passo que o marketing territorial foca na otimização de vantagens competitivas e no desenvolvimento cooperativo de identidade, imagem, posicionamento e marca das empresas, áreas industriais e municípios desta região, é imprescindível uma transformação que converta as limitações e as ameaças em oportunidades e diferenciais competitivos e colaborativos no território. Tal transformação deve considerar reconfigurações nos 4Ps do mix de marketing diante da realidade contextual dos atores e dinâmicas envolvidos.

Nestas dinâmicas, as inter-relações apontam para a necessidade de maior valorização e proximidade do poder público em relação às indústrias, no que condiz quanto às suas demandas e potencialidades. É preciso, ainda, instigar todos os agentes a participarem ativamente nos processos e dinâmicas territoriais, possibilitando que as áreas industriais se convertam em distritos industriais eficazes, por meio da valorização da aprendizagem, do conhecimento e de ações inovadoras compartilhadas e aplicadas, abrangendo não apenas a dimensão econômica, mas também as dimensões social, cultural e ambiental. É esta reconfiguração socioterritorial que contribuirá para tornar o território mais competitivo, conceituado e sustentável.

Desta forma, constatam-se contribuições teóricas e práticas do estudo para abordagens relacionadas aos distritos industriais e ao marketing territorial, e sua relevância para acadêmicos, docentes e teóricos das áreas da administração e do desenvolvimento regional, bem como 
para agentes públicos e privados envolvidos em projetos de implementação e consolidação de distritos industriais e outros tipos de aglomerações produtivas locais.

Para complementação o estudo, sugerem-se pesquisas com outros agentes participativos nas dinâmicas de desenvolvimento das áreas industriais. Para maior contribuição, recomendam-se pesquisas de marketing territorial em outros tipos de aglomerações produtivas. E, para investigar novos contextos, sugerem-se estudos de caso ou multicaso em distritos industriais e demais aglomerações produtivas de outras regiões e de outras escalas territoriais mais amplas.

\section{REFERÊNCIAS}

ALBAGLI, S.; MACIEL, M. L. Informação e conhecimento na inovação e no desenvolvimento local. Ciência da Informação, Brasília, v. 33, n. 3, p. 9-16, set./dez. 2004.

ARAGONEZ, T.; ALVES, G. C. Marketing territorial: o futuro das cidades sustentáveis e de sucesso. Tourism \& Management Studies: Faro, v. 1, p. 316-19, 2013.

BAUER, R. Gestão da mudança: caos e complexidade nas organizações. São Paulo: Atlas, 1999.

BECATTINI, G. The marshallian industrial district as a socio-economic notion. In: PIKE, F.; BECATTINI, G.; SENGENBERGER, W. (Ed.). Industrial districts and interfirm cooperation in Italy.: Geneva: International Institute for Labour Studies [ILO], 1990.

CARGNIN, A. P. Política de desenvolvimento regional no Rio Grande do Sul: vestígios, marcas e repercussões territoriais. 2011. 318 f. Tese (Doutorado em Geografia) - Universidade Federal do Rio Grande do Sul, Porto Alegre, RS, 2011.

DALLABRIDA, V. R.; SIEDENBERG, D. R.; FERNÁNDEZ, V. R. Desenvolvimento a partir da perspectiva territorial. Desenvolvimento em Questão, ljuí, ano 2, n. 4, p. 33-62, jul./dez. 2004.

DALLABRIDA, V. R.; TOMPOROSKI, A. A.; SAKR, M. R. Do marketing territorial ao branding de território: concepções teóricas, análises e prospectivas para o Planalto Norte Catarinense. Interações, Campo Grande, MS, v. 17, n. 4, p. 671-85, out./dez. 2016.

FERNANDES, R.; GAMA, R. A cidade digital versus a cidade inteligente: estratégias de desenvolvimento sócio-econômico e/ou de marketing territorial. In: CONGRESSO LUSO-BRASILEIRO PARA O PLANEJAMENTO URBANO, REGIONAL, INTEGRADO E SUSTENTÁVEL, 2., 2006, Braga. Anais [...]. Braga: Universidade do Minho, 2006a.

FERNANDES, R.; GAMA, R. As cidades e territórios do conhecimento na óptica do desenvolvimento e do marketing territorial. In: COLÓQUIO DA ASSOCIAÇÃO PORTUGUESA DE DESENVOLVIMENTO REGIONAL, 5., 2006, Viseu. Anais [...]. Viseu: Escola Superior de Tecnologia e Gestão de Viseu, 2006b.

FÓRUM DOS COREDES. Planos estratégicos de desenvolvimento dos COREDEs 2015-2030: perspectivas estratégicas das Regiões Funcionais. 1. ed. Lajeado: Univates, 2017. 199p.

GAIO, S.; GOUVEIA, L. B. O branding territorial: uma abordagem mercadológica à cidade. Revista A Obra Nasce, p. 27-36, 2007.

KELLER, P. F. Clusters, distritos industriais e cooperação interfirmas: uma revisão da literatura. Revista Economia \& Gestão, Belo Horizonte, v. 8, n. 16, p. 30-47, set. 2008.

KOTLER, P.; HAIDER, D. H.; REIN, I. Marketing places: attracting investment, industry, and tourim to cities, states, and nations. New York: Free Press, 1993. 
KUTTUBAEVA, T. A.; ISHCHUK, L. V.; ADARINA, R. T.; GLOTKO, A. V.; FEDOSOVA, T. V. Applications of the concept of territorial marketing in forming and implementing competitive advantages for tourist areas. Journal of Environmental Management and Tourism, v. 8, n. 20, p. 713-26, 2017.

LIMA, E. C.; NETO, C. R. O. Análise do desenvolvimento territorial: a contribuição da experiência italiana. Interações, Campo Grande, MS, v. 20, n. 1, p. 51-61, jan./mar. 2019.

MALHOTRA, N. K. Pesquisa de marketing: uma orientação aplicada. 6. ed. Porto Alegre: Bookman, 2012.

MINAYO, M. C. S. (Org.) Pesquisa social: teoria, método e criatividade. Petrópolis: Vozes, 2016.

OLIVEIRA, H. S. Gestão urbana e investimento industrial: considerações sobre o parque automotivo da região metropolitana de Curitiba. Revista Gestão Industrial, Curitiba, v. 1, n. 1, p. 104-17, 2005.

OLIVEIRA, L. Y. Q.; BORGES, P. P. O direito à cidade e o desenvolvimento local como base para a humanização do espaço urbano. Interações, Campo Grande, MS, v. 19, n. 4, p. 739-55, out./dez. 2018.

PORTO ALEGRE (Estado). Secretaria do Planejamento, Mobilidade e Desenvolvimento Regional. PPA 20162019: Cadernos de Regionalização - Região Funcional 7. Porto Alegre, 2015. 108 p.

PUTNAM, R. D. Comunidade e democracia: a experiência da Itália moderna. Rio de Janeiro: FGV, 1996.

RIZZI, P.; CICIOTTI, E.; GRAZIANO, P. The role of cities in economic development and the challenges of territorial marketing and place branding. In: BAUSSOL, M.; BELLAVIT, C.; VIVARELL, M. (Ed.). Essays in honor of Luigi Campiglio. Milão: Vita e Pensiero, 2018. p. 173-196.

TIDD, J.; BESSANT, J. Inovação: o que é e por que importa? In: TIDD, J.; BESSANT, J. (Org.). Gestão da Inovação. 5. ed. Porto Alegre: Bookman, 2015. p. 3-54.

VILLASCHI FILHO, A.; CAMPOS, R. R. Sistemas/arranjos produtivos localizados: conceitos históricos para novas abordagens. In: CASTILHOS, C. C. (Coord.). Programa de apoio aos sistemas locais de produção: a construção de uma política pública no RS. Porto Alegre: FEE; SEDAI, 2002. p. 11-48.

\section{Sobre os autores:}

Juliana da Fonseca Capssa Lima Sausen: Doutoranda do Programa de Pós-Graduação Stricto Sensu em Desenvolvimento Regional da Universidade Regional do Noroeste do Estado do Rio Grande do Sul (UNIJUÍ). Bolsista Prosuc/Capes (UNIJUí). E-mail: jucapssa@gmail.com, Orcid: http://orcid.org/0000-0003-4146-8294

Jorge Oneide Sausen: Doutor em Engenharia da Produção e Pós-Doutor em Administração. Professor doutor do Programa de Pós-Graduação Stricto Sensu em Desenvolvimento Regional da Universidade Regional do Noroeste do Estado do Rio Grande do Sul (UNIJUí). E-mail: josausen@unijui.edu.br, Orcid: http://orcid.org/0000-0003-3684-1410

Daniel Knebel Baggio: Doutor em Contabilidade e Finanças. Professor doutor do Programa de Pós-Graduação Stricto Sensu em Desenvolvimento Regional da Universidade Regional do Noroeste do Estado do Rio Grande do Sul (UNIJUÍ). E-mail: baggiod@unijui.edu.br, Orcid: http://orcid.org/0000-0002-6167-2682

Sérgio Luís Allebrandt: Doutor em Desenvolvimento Regional. Coordenador e professor doutor do Programa de Pós-Graduação Stricto Sensu em Desenvolvimento Regional da Universidade Regional do Noroeste do Estado do Rio Grande do Sul (UNIJUí). E-mail: allebr@unijui.edu.br, Orcid: http://orcid.org/0000-0002-2590-6226 